\title{
The impact of advanced age on short-term outcomes following gastric cancer resection: an ACS-NSQIP analysis
}

\author{
Trevor D. Hamilton ${ }^{1,2} \cdot$ Alyson L. Mahar ${ }^{3} \cdot$ Barbara Haas $^{4,5} \cdot$ Kaitlyn Beyfuss $^{5} \cdot$ Calvin H. L. Law $^{4,5} \cdot$ \\ Paul J. Karanicolas ${ }^{4,5} \cdot$ Natalie G. Coburn ${ }^{4,5}$. Julie Hallet ${ }^{4,5}$
}

Received: 4 September 2017 / Accepted: 1 December 2017 / Published online: 11 December 2017

(c) The International Gastric Cancer Association and The Japanese Gastric Cancer Association 2017

\begin{abstract}
Background Evidence on short-term outcomes for GC resection in elderly patients is limited by small samples from singleinstitutions. This study sought to examine the association between advanced age and short-term outcomes of gastrectomy for gastric cancer (GC).

Methods Using ACS-NSQIP data, patients undergoing gastrectomy for GC (2007-2013) were identified. Primary outcome was 30-day major morbidity. Outcomes were compared across age categories $(<65,65-70,71-75,76-80,>80$ years old). Univariable and multivariable regression was used to estimate the morbidity risk associated with age.

Results Of 3637 patients, $60.6 \%$ were $\geq 65$ years old. Major morbidity increased with age, from $16.3 \%$ ( $<65$ years old) to $21.5 \%$ (76-80 years old), and $24.1 \%$ ( $>80$ years old) $(p<0.001)$, driven by higher respiratory and infectious events. Perioperative 30-day mortality increased from $1.2 \%$ (<65years old) to $6.5 \%$ ( $>80$ years old) $(p<0.0001)$. After adjustments, age was independently associated with morbidity for 76-80 years of age (RR 1.31, 95\% CI, 1.08-1.60) and $>80$ years old (RR $1.49,95 \%$ CI, $1.23-1.81$ ). Predicted morbidity increased by $18.6 \%$ in those $75-80$ years old and $27.5 \%$ in those $>80$ years old (compared to $<65$ years old) for total gastrectomy, and by $11.6 \%$ and $17.2 \%$ for subtotal gastrectomy, for worst case scenario. Morbidity increased by $5.1 \%$ in those $75-80$ years old and $7.6 \%$ in those $>80$ years old for total gastrectomy, and by $3.1 \%$ and $4.7 \%$ for subtotal gastrectomy, for best case scenario.

Conclusions Advanced age, defined as more than 75 years, was independently associated with increased morbidity after GC resection. The magnitude of this impact is further modulated by clinical scenarios. Increased risk in elderly GC patient should be recognized and considered in indications for resection.
\end{abstract}

Keywords Gastric cancer $\cdot$ Resection $\cdot$ Elderly $\cdot$ Morbidity $\cdot$ Mortality

\section{Introduction}

Part of this study was presented as a poster presentation at the Annual Cancer Symposium held in Boston, MA, USA in March 2016, and as oral presentation at the Canadian Surgery Forum held in Toronto, ON, Canada in September 2016, and has been submitted for presentation at the Congrès Français de Chirurgie (to be held).

Electronic supplementary material The online version of this article (https://doi.org/10.1007/s10120-017-0786-6) contains supplementary material, which is available to authorized users.

Julie Hallet

julie.hallet@sunnybrook.ca

Extended author information available on the last page of the article
By $2030,20 \%$ of the American population will be over the age of 65 [1]. These demographic changes represent a significant burden in oncology care. The risk of developing cancer increases with age, up to $33 \%$ within the age range between 60 and 79 years old [2. By 2030, nearly three quarters of all cancers will be diagnosed in individuals more than 65 years old.

Managing patients of advanced age poses special challenges to surgical oncologists. Older patients are living more active lives and are increasingly offered more invasive procedures [3]. Balancing patients' hope for curative intervention with the risks posed by an increased burden of comorbidities, frailty, and shortened life expectancy renders the assessment of risks and benefits of complex surgical interventions 
difficult. Surgeons are often expected to provide the same care and procedures regardless of age.

These challenges are particularly relevant in the management of gastric cancer (GC), which affects patients with a median age of 66-69 years in Western countries [4]. Surgery remains the only potential curative intent treatment. Even in highly selected populations, morbidity and mortality following curative intent surgical resection for GC are considerable (up to $46 \%$ and $4.7 \%$, respectively) [5]. Furthermore, the exact extent of surgery is still debated (lymphadenectomy, margins, and multi-visceral resections), and 5-year overall survival is limited at $36 \%$ with multimodal therapy [6-8]. Thus, it is both important and difficult to balance the longterm oncological benefits of gastrectomy for cancer with the invasiveness of surgery and perioperative risks when deciding on resection for GC in older patients.

Decision making is further complicated by the lack of robust procedure-specific data regarding surgical risk and outcomes in older patients undergoing gastrectomy for GC. The evidence on this issue is mostly limited to small, conflicting reports from single institutions [9-18]. Moreover, the generalizability of data from Eastern series to a Western population is unclear given the different patient populations with GC $[9,11-13,15,16,19]$.

This study sought to examine the short-term outcomes of gastrectomy for GC in elderly patients in a Western population and to define factors associated with adverse outcomes with advancing age.

\section{Methods}

\section{Study design}

A retrospective cohort study of patients undergoing elective gastrectomy for GC was conducted. Approval was sought through the Sunnybrook Health Sciences Centre Research Ethics Board, and the study was deemed to be exempt. The study was conducted and reported according to the recommendations of the RECORD statement [20].

This study used the American College of Surgeons National Surgical Quality Improvement Program (ACSNSQIP) registry data. This multi-institutional registry collects perioperative data to provide participating institutions with risk-adjusted outcomes for quality improvement initiatives. It includes more than 500 low- and high-volume academic and community centers located most commonly in North America (American College of Surgeons: Z0hWdNLG). For privacy reasons, the institutions cannot be identified in the ACS-NSQIP participant user file. ACSNSQIP abstractor training, data collection, and audit methods have previously been reported [21-24].

\section{Study cohort}

Patients undergoing an elective gastric cancer resection between 2007 and 2013 at participating ACS-NSQIP institutions were eligible. GC patients were identified using ICD-9 codes (151.x), and the population was restricted to those receiving a gastrectomy using procedural codes (Supplemental Digital Content Table 1). Individuals were excluded for age less than 18 years, emergency surgery, metastatic disease, and missing data on key variables necessary for the analysis (gender, ASA class, body mass index, functional health status, preoperative serum creatinine, preoperative hematocrit, and operative time). There were no missing data on age. Missing data were encountered in $<0.05 \%$ for gender, $0.1 \%$ for operative time, $0.2 \%$ for ASA class and functional health status, $0.8 \%$ for preoperative hematocrit, $1.2 \%$ for body mass index, and $3 \%$ for preoperative serum creatinine. The extent of missing data did not vary significantly by age category.

\section{Exposure}

Patient age was the main variable of interest. Definitions regarding older age in surgical patients are not clear [25]. Therefore, we divided a conservative elderly group of patients older than 65 years into sub-categories to better appreciate the impact of the entire spectrum of older age and the incremental risk of different age cutoffs.

\section{Outcomes}

The primary outcome of interest was 30-day major morbidity. The major morbidity composite outcome was defined as the occurrence of one or more of the following: deep or organ-space surgical site infection (SSI), wound dehiscence, pneumonia, pulmonary embolism, unplanned intubation, prolonged ventilation $(>48 \mathrm{~h}$ ), unplanned reintubation, renal failure, sepsis, septic shock, myocardial infarction, cardiac arrest, or cerebral vascular accident (CVA) [26-28]. Secondary outcomes included system-specific 30-day morbidity grouped into infectious events, cardiac events, respiratory failure, venous thromboembolic events, unplanned reoperation, postoperative mortality within 30 days of operation, and hospital length of stay (LOS).

\section{Covariates}

Demographics, clinical characteristics, diagnostic, and treatment-related details were extracted from the ACSNSQIP registry. The World Health Organization definition of anemia was used, i.e., hematocrit less than $40 \%$. Surgical 
procedures were divided into total gastrectomy, sub-total gastrectomy, and multi-visceral resection (Supplemental Digital Content Table 1).

Relevant patient and operative characteristics were identified a priori as potential confounders of the relationship between age and the perioperative outcomes of interest. Covariates were selected based on temporality (known preoperatively), clinical relevance (considered when assessing a patient for risk of adverse perioperative events), and existing literature (established relationship with worse surgical outcomes). A parsimonious set of covariates was selected to maintain adequate study power. The following covariates were ultimately included: gender, body mass index (BMI), preoperative respiratory and cardiovascular comorbidities, diabetes, preoperative weight loss $(>10 \%)$, and surgical procedure.

\section{Analysis}

The characteristics of elderly patients were described and compared by age groups. Unknown categories were created for missing data. Categorical data were reported as absolute number $(n)$ and proportion (\%), and continuous data as mean or median with interquartile range (IQR). Chi-squared tests for independence were used to compare categorical variables. Normally distributed continuous data were compared using $t$ tests and skewed continuous data using Wilcoxon rank-sum tests.

Modified Poisson regression analysis was used to examine the association between age category and morbidity for common outcomes $(>10 \%)$, and logistic regression for uncommon outcomes $(\leq 10 \%)$. Results are reported as relative risks (RR) with 95\% confidence intervals (95\% CI). Multivariable analyses were adjusted for previously described covariates defined a priori.

In the second part of our analysis, we utilized a modified Poisson regression model to predict the probability of major morbidity for different patient and operative profiles. Variables included in this model were age (categories), BMI, functional status, history of cardiac disease, history of diabetes, history of respiratory disease, and type of operation. The probability of major complications was presented for each age category for a best case scenario (female gender, low BMI, independent functional status, no comorbidities) and worst case scenario (male gender, high BMI, depending functional status, comorbidities). Model fit was evaluated using the quasi-likelihood criterion statistic: values closer to 1 indicate better fit.

All statistical analyses were conducted using SAS 9.3 for Windows (SAS Institute, Cary, NC, USA). $p$ values $<0.05$ were considered statistically significant. A.L.M. and J.H. had full access to the data in the study and take responsibility for the integrity of the data and the accuracy of the data analysis.

\section{Results}

\section{Cohort characteristics}

A total of 4215 patients who underwent gastrectomy for GC between 2007 and 2013 were identified in the ACSNSQIP registry, of whom 578 were excluded (Fig. 1). The final study cohort thus included 3637 patients. Of included patients, $2203(60.6 \%)$ were over the age of 65 and 551 $(15.0 \%)$ over the age of 80 . Baseline characteristics of the cohort, stratified by age category, are shown in Table 1. ASA class IV-V and partially/totally dependent functional health status were more common among those more than 80 years old, and cardiac comorbidities more frequent among patients more than 75 years old. Although total gastrectomy was less frequent after age 75 , no difference was observed in the frequency of multi-visceral resection.

\section{Outcomes}

Postoperative outcomes are presented stratified by age category in Fig. 2. For the entire cohort, 30-day major

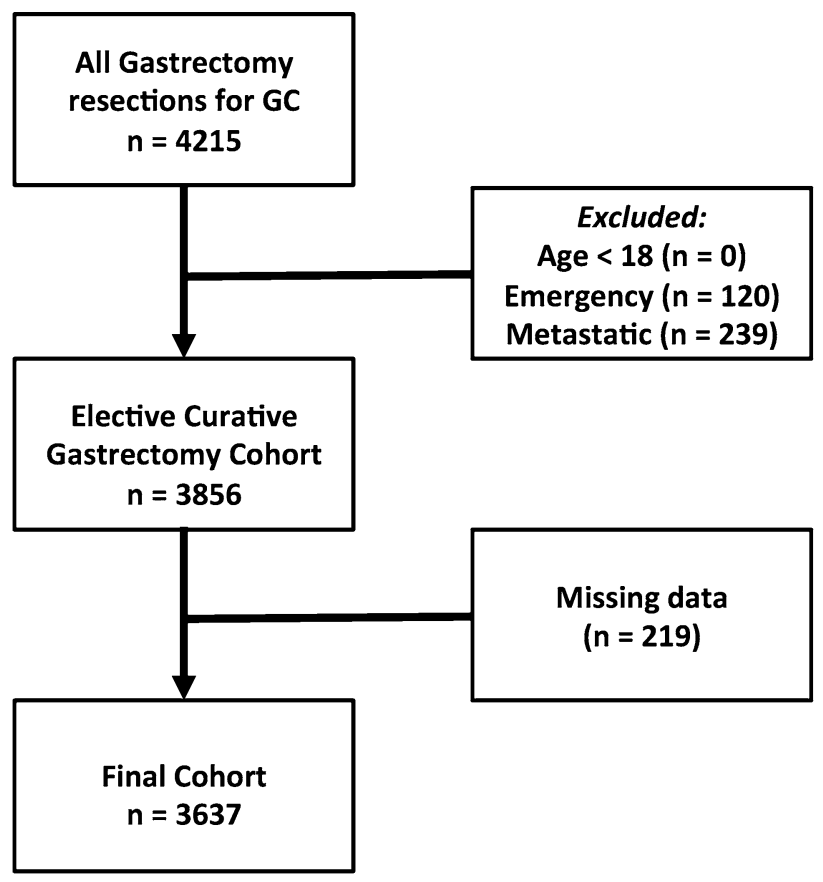

Fig. 1 Flow diagram of cohort creation from the American College of Surgeons National Surgical Quality Improvement Program (ACSNSQIP) data registry. *Missing data on key variables: gender, ASA class, body mass index, functional health status, preoperative serum creatinine, preoperative hematocrit, and operative time 
Table 1 Demographic and clinical characteristics of the overall cohort with stratification by age group

\begin{tabular}{|c|c|c|c|c|c|c|c|}
\hline \multirow[t]{2}{*}{ Factor } & & \multirow{2}{*}{$\begin{array}{l}\text { Non-elderly } \\
<65 \text { years } \\
\text { old } \\
(n=1434)\end{array}$} & \multicolumn{4}{|l|}{ Elderly } & \multirow[t]{2}{*}{$P$ value } \\
\hline & & & $\begin{array}{l}65-70 \text { years } \\
\text { old }(n=481)\end{array}$ & $\begin{array}{l}71-75 \text { years } \\
\text { old }(n=567)\end{array}$ & $\begin{array}{l}76-80 \text { years } \\
\text { old }(n=604)\end{array}$ & $\begin{array}{l}>80 \text { years old } \\
(n=551)\end{array}$ & \\
\hline \multicolumn{2}{|l|}{ Female gender } & $626(43.7)$ & $188(39.1)$ & 208 (36.7) & $242(40.1)$ & $267(48.5)$ & 0.0005 \\
\hline \multirow{4}{*}{$\begin{array}{l}\text { Body mass index }(\mathrm{kg} / \\
\left.\mathrm{m}^{2}\right)\end{array}$} & $<20$ & $128(8.93)$ & & 47 (8.29) & $54(8.94)$ & $81(14.70)$ & $<0.0001$ \\
\hline & $20-30$ & 953 (66.46) & & 377 (66.49) & 436 (72.19) & $379(68.78)$ & \\
\hline & $31-40$ & $298(20.78)$ & & $127(22.40)$ & $103(17.05)$ & $86(15.61)$ & \\
\hline & $>40$ & $55(3.84)$ & & $16(2.82)$ & $11(1.82)$ & $5(0.91)$ & \\
\hline \multirow[t]{4}{*}{ Race } & White & $620(43.24)$ & $238(49.48)$ & $300(52.91)$ & $326(53.97)$ & $315(57.17)$ & $<0.0001$ \\
\hline & Black & $251(17.50)$ & 35 (7.28) & $80(14.11)$ & $76(12.58)$ & $52(9.44)$ & \\
\hline & Other & $218(15.20)$ & 315 (65.49) & $70(12.35)$ & 67 (11.09) & $63(11.43)$ & \\
\hline & Unknown & 345 (24.06) & $116(24.12)$ & $117(20.63)$ & $135(22.35)$ & $121(21.96)$ & \\
\hline \multirow[t]{4}{*}{ ASA class } & I & 30 (2.09) & $15(3.12)$ & $4(0.71)$ & $2(0.33)$ & $2(0.36)$ & $<0.0001$ \\
\hline & II & 605 (42.19) & 125 (25.99) & $127(22.40)$ & $122(20.20)$ & 98 (17.79) & \\
\hline & III & $762(53.14)$ & & $390(68.78)$ & $420(69.54)$ & $381(69.15)$ & \\
\hline & IV-V & $37(2.58)$ & & $46(8.11)$ & $60(9.93)$ & $70(12.70)$ & \\
\hline \multirow[t]{2}{*}{ Functional health status } & Independent & $1404(97.91)$ & & $541(95.41)$ & $564(93.38)$ & $492(89.29)$ & $<0.0001$ \\
\hline & $\begin{array}{l}\text { Partially/totally } \\
\text { dependent }\end{array}$ & $30(2.09)$ & & $26(4.59)$ & $40(6.62)$ & $59(10.71)$ & \\
\hline \multicolumn{2}{|c|}{ Preoperative weight loss $(>10 \%)$} & $242(16.88)$ & $322(66.94)$ & $91(16.05)$ & $75(12.42)$ & $76(13.79)$ & 0.0361 \\
\hline \multicolumn{2}{|c|}{ Preoperative steroids medication } & $27(1.88)$ & $31(6.44)$ & $18(3.17)$ & $13(2.15)$ & $14(2.54)$ & 0.5151 \\
\hline \multirow[t]{4}{*}{ Comorbidities } & Diabetes & $471(97.92)$ & $116(24.12)$ & $141(24.01)$ & $145(24.01)$ & $107(19.42)$ & $<0.0001$ \\
\hline & Respiratory (COPD) & $10(2.08)$ & $21(4.37)$ & $41(7.23)$ & $45(7.45)$ & $46(8.35)$ & $<0.0001$ \\
\hline & Cardiac & $508(35.43)$ & $309(64.24)$ & $379(66.84)$ & $447(74.01)$ & $423(76.77)$ & $<0.0001$ \\
\hline & Bleeding disorder & $36(2.51)$ & $11(2.29)$ & $26(4.59)$ & $31(5.13)$ & $27(4.90)$ & 0.0035 \\
\hline \multirow{3}{*}{$\begin{array}{l}\text { Preoperative laboratory } \\
\text { values }\end{array}$} & Creatinine (mg/dl) & $0.89(0.51)$ & $0.94(0.48)$ & $1.02(0.58)$ & $1.06(0.52)$ & $1.11(0.70)$ & $<0.0001$ \\
\hline & Albumin $(\mathrm{g} / \mathrm{dl})$ & $3.86(0.62)$ & $3.77(0.57)$ & $3.69(0.61)$ & $3.67(0.60)$ & $3.52(0.63)$ & $<0.0001$ \\
\hline & Hematocrit (\%) & $36.80(5.29)$ & $36.20(5.48$ & $35.86(5.43)$ & $35.63(5.47)$ & $34.61(4.90)$ & $<0.0001$ \\
\hline \multicolumn{2}{|l|}{ Operative time (min) } & $244(113)$ & $235(110)$ & $233(93)$ & $215(96)$ & $199(91)$ & $<0.0001$ \\
\hline \multirow[t]{2}{*}{ Extent of gastrectomy } & Total & 595 (41.49) & $211(43.87)$ & $215(37.92)$ & $175(28.97)$ & $128(23.23)$ & $<0.0001$ \\
\hline & Sub-total & $839(58.51)$ & $270(56.13)$ & $352(62.08)$ & $429(71.03)$ & $423(76.77)$ & \\
\hline \multirow[t]{7}{*}{ Multi-visceral resection } & All & $156(10.88)$ & $46(9.56)$ & $51(8.99)$ & $62(10.26)$ & $52(9.44)$ & 0.7066 \\
\hline & Spleen & $31(2.16)$ & $13(2.70)$ & $16(2.82)$ & $18(2.98)$ & $4(0.73)$ & \\
\hline & Colon & $28(1.95)$ & $9(1.87)$ & $18(3.17)$ & $8(1.32)$ & $14(2.54)$ & \\
\hline & Pancreas & $38(2.65)$ & $10(2.08)$ & $10(1.76)$ & $8(1.32)$ & $8(1.45)$ & \\
\hline & Small bowel & $27(1.88)$ & $9(1.87)$ & $12(2.12)$ & $14(2.32)$ & $15(2.72)$ & \\
\hline & Liver & $66(4.60)$ & $20(4.16)$ & $17(3.00)$ & $34(5.63)$ & $18(3.27)$ & \\
\hline & Esophagus & $15(1.05)$ & $3(0.62)$ & $3(0.53)$ & $3(0.50)$ & $2(0.36)$ & \\
\hline
\end{tabular}

Values are $n(\%)$ and mean (standard deviation)

$A S A$ American Society of Anesthesiology, COPD chronic obstructive pulmonary disease

morbidity occurred in $19.6 \%$ of cases and increased with advancing age $(p<0.001)$. This incremental morbidity was driven by increasing frequency of infectious, respiratory and cardiac complications with advancing age. The overall 30-day post-operative mortality in the cohort was $3.1 \%$. As with complications, mortality also increased with advancing age $(p<0.001)$.
Median LOS was 9 (IQR: 7-13) days for the entire cohort and varied according to age category, with respectively 8 (IQR:6-12) days, 9 (IQR:7-13) days, 9 (IQR:7-13) days, 9 (IQR: 7-14) days, and 10 (IQR: 7-15) days respectively for patients $<65,65-70,71-75,76-80$ and $>80$ years old $(p<0.001)$. 


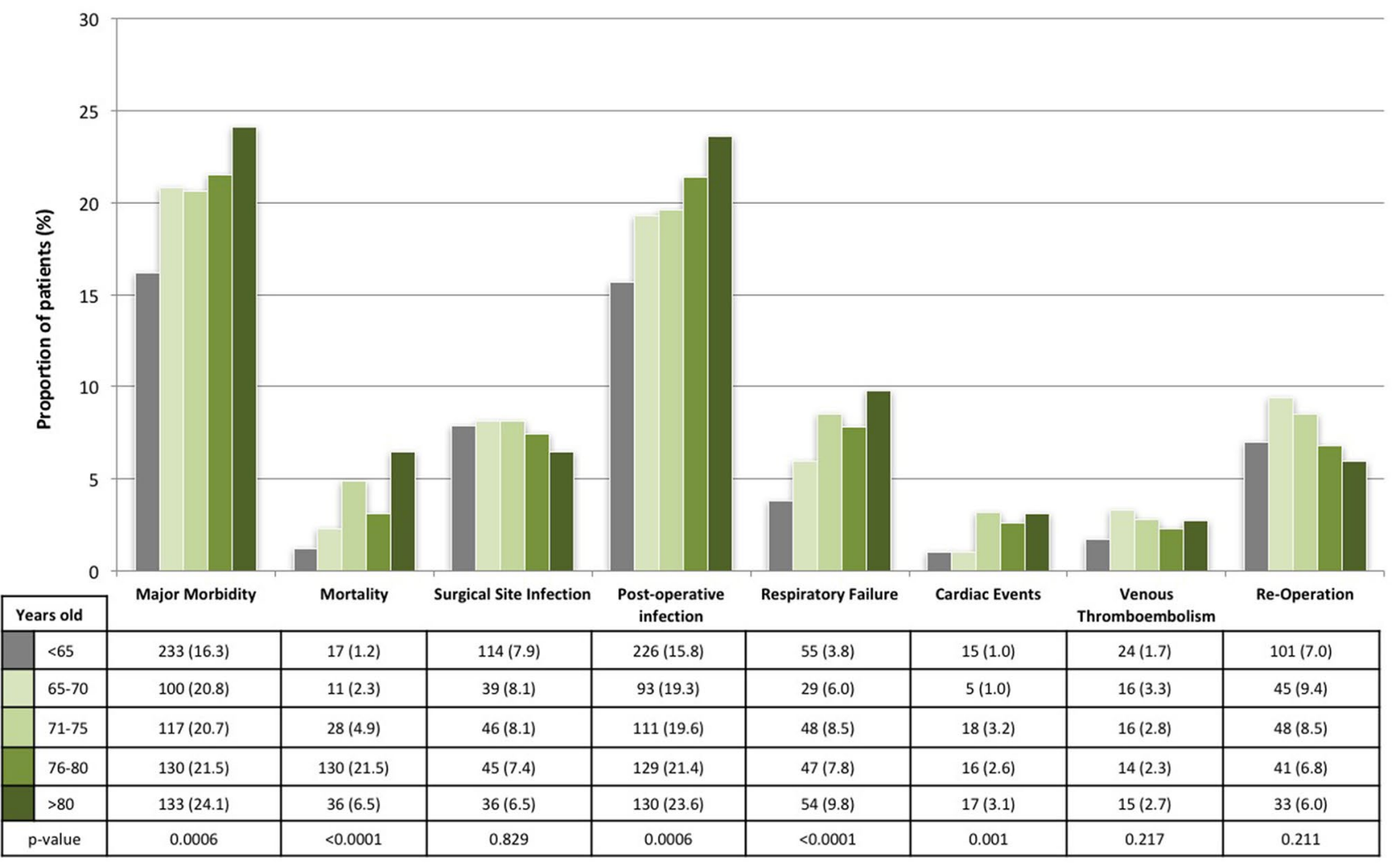

Fig. 2 Postoperative (30-day) outcomes in the entire cohort, stratified by age category

After adjusting for relevant clinical variables defined a priori, age was independently associated with increased major morbidity among patients $76-80$ years old (RR 1.31, 95\% CI 1.08-1.60) and > 80 years old (RR $1.49,95 \%$ CI 1.23-1.81) (Fig. 3).

\section{Pre-operative morbidity risk estimation}

A multivariable predictive model for major morbidity including relevant clinical variables known pre-operatively was created (Supplemental Digital Content Tables 2, 3, 4). The variables included were age, gender, BMI, functional health status, extent of surgery, diabetes, and cardiovascular and respiratory comorbidities. The incremental risk of morbidity was assessed for the age categories identified as independently associated with worse higher morbidity in the prior multivariable analysis (75-80 years old, and $>80$ years old).

Sets of adverse and optimal pre-operative characteristics was defined based on the results of the prior multivariable analysis. Assuming adverse pre-operative characteristics (male gender, high BMI, depending functional health status, any comorbidity of cardiovascular, respiratory, and diabetes), predicted major morbidity for total gastrectomy presented an absolute increase of $18.6 \%$ in $75-80$ years old and $27.5 \%$ in $>80$ years old groups, compared to $<65$ years old, and by 11.6 and $17.1 \%$ for subtotal gastrectomy. With optimal pre-operative characteristics (female gender, low BMI, independent functional health status, no comorbidities), major morbidity for total gastrectomy increased by $5.1 \%$ in $75-80$ years old and $7.6 \%$ in $>80$ years old groups, compared to $<65$ years old, and by 3.1 and $4.7 \%$ for subtotal gastrectomy (Fig. 4).

\section{Discussion}

This study identified that elderly patients over age 75 are at progressively higher risk for major morbidity and mortality after gastrectomy for GC, independently of preoperative comorbidities and functional health status. The higher overall postoperative morbidity is driven by increased risk of postoperative infections, respiratory failure, and cardiac events. Although the risk was increased in all elderly patients, the magnitude of the increase varied depending on other clinical characteristics, including preoperative comorbidities and the extent of resection.

This study represents the largest multi-institutional assessment of the impact of age on outcomes following gastrectomy for GC. Most of the evidence on this topic comes 


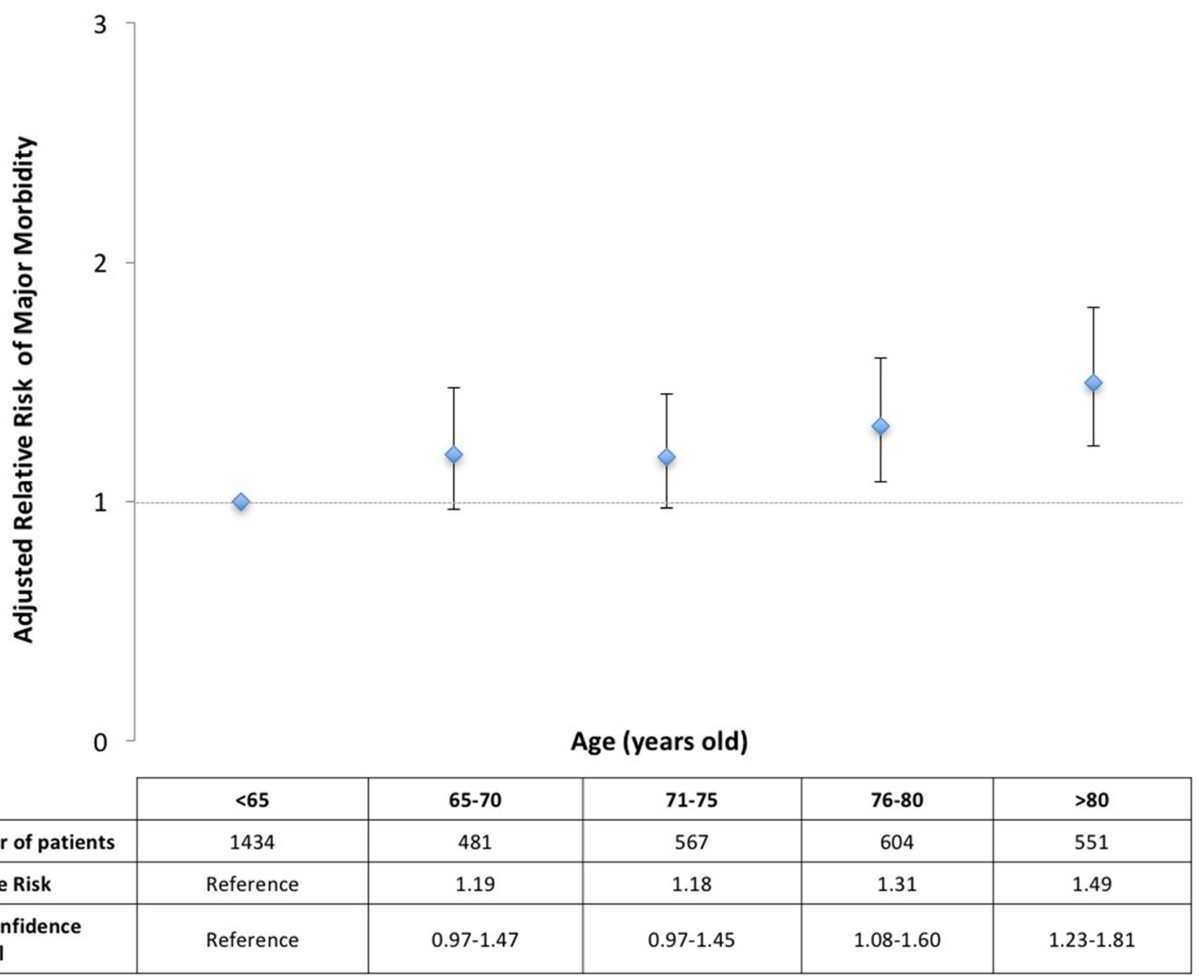

Fig. 3 Relative risk of major morbidity based on age category adjusted for gender, body mass index (BMI), preoperative respiratory and cardiovascular comorbidities, diabetes, weight loss, and surgical procedure

from single-center underpowered Eastern studies [9-13, 15, 16, 19, 29]. Although some of these studies have reported increased postoperative morbidity in the elderly population $[9,11,17]$, the majority observed no significant differences $[10,12,13,15,16]$. Most patients in these studies were treated laparoscopically for earlier-stage GC, which is not representative of the Western GC population that is mostly treated for locally advanced disease with laparotomy [4]. Western studies also did not observe any difference in outcomes for older patients, but suffer from the same methodological shortcomings regarding single-center cohorts and small sample sizes. [14, 30]. One multi-institutional analysis recently outlined higher morbidity and mortality in 127 patients in the US more than 80 years old [18]. All those reports remain limited by reporting bias from retrospective data collection.

Larger studies using prospectively collected, standardized, and audited data (including the ACS-NSQIP) indicated a higher proportion of postoperative morbidity and mortality among the elderly in a mix of abdominal cancer surgeries [25, 31]. Gastrectomy for GC presents unique risks because of the high technical demand of the procedure and the preoperative impact of the cancer on the patient's performance resulting from nutritional impairment and anemia. The current analysis represents a relevant addition to the literature by providing a detailed procedure-specific assessment of incremental morbidity and mortality risk in a large Western population using multi-institutional prospectively collected and standardized contemporary data.

The traditional definition of elderly relies on an arbitrary age cutoff determined by the retirement age in developed nations: 60 years old according to the United Nations and 65 years old according to the World Health Organization $[32,33]$. In studies addressing GC, the age cutoff to define elderly patients is highly variable, from 70 to 80 years old [9, $10,12,14-16,19,34-36]$. One assessment of aging in the surgical setting determined that 68.5 years was the optimal cutoff in terms of sensitivity and specificity to predict morbidity. It further revealed that "extreme old age" started at 75 years old [25]. In the current study, older age was broken down in categories over the age of 65 years to avoid biases from choosing a single cutoff; this provides an appreciation of incremental risk over the continuum of older age rather than a dichotomous change in risk based on an arbitrary cutoff. 


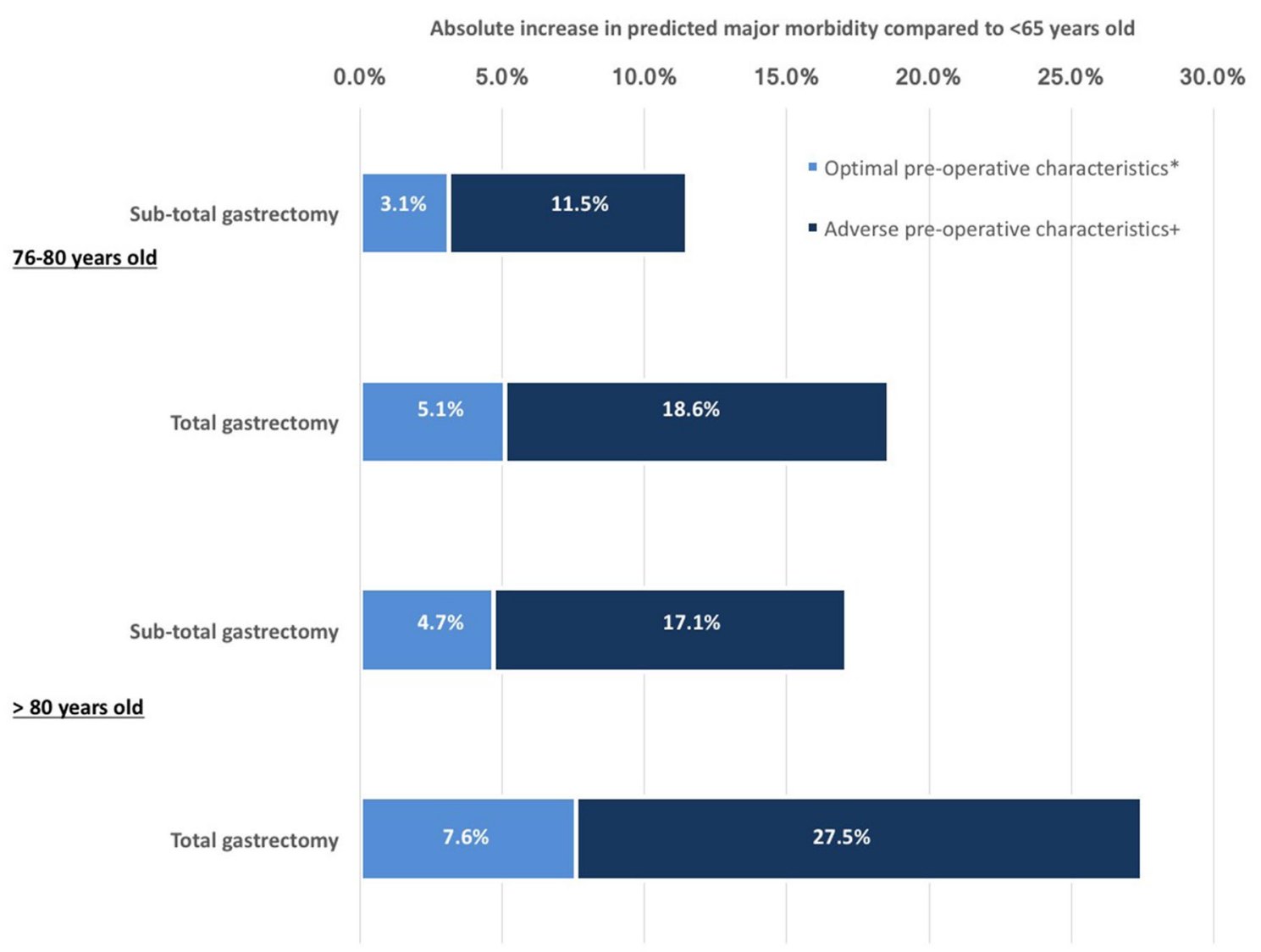

Fig. 4 Absolute increase in predicted major morbidity compared to non-elderly patients ( $<65$ years old). *Male gender, high BMI, depending functional health status, any comorbidity (cardiovascular,

The elderly population is unique in the provision of surgical cancer care. Worse outcomes can be related to a higher comorbidity burden that adds to the physiological stress of major surgery, heavier impact of cancer on preoperative systemic and functional status (e.g., nutrition, fatigue), and frailty present even in individuals without comorbidities or considered "highly functioning." The identification of higher risk for postoperative morbidity is highly relevant in optimizing not only short-term but also long-term outcomes. Once morbidity occurs in the elderly, it has a more aggravated course and failure to rescue is more likely [3, 25, 37]. Postoperative complications often preclude the use of adjuvant therapy necessary for optimal oncological outcomes for GC [38, 39].

In this study, older age was independently associated with increased risk of morbidity and mortality after GC resection. Chronological age should be considered as an individual risk factor, with more pronounced incremental risk after the ages of 75 and 80 years. The magnitude of increased morbidity risk is further modulated by comorbidities and the extent of resection. This finding was highlighted in the scenarios based on the predictive model. This model was not respiratory, diabetes). ${ }^{+}$Female gender, low BMI, independent functional health status, no comorbidities

developed for use in daily clinical practice to predict individual risk. Rather, it was meant to illustrate incremental risk through common scenarios to help surgeons contextualize the results to clinical practice. These numbers demonstrate that particular attention should be paid to patients beyond the ages of 75 and 80 years, as comorbidities when added to baseline chronological age increased risk. Our model adds to the available evidence and existing clinical risk scores, including those developed by the ACS-NSQIP. Indeed, ACS-NSQIP risk calculators have been developed in mixed populations operated on for a variety of surgical procedures. Unfortunately, these risk calculators lack procedure- and disease-specific value, and their clinical use appears to be limited in some settings [40, 41].

Invasive surgery is increasingly offered to elderly patients so as to not deny them what is considered the standard of care $[3,42]$. This approach is confirmed by the comparable frequency of multi-visceral resection across all age groups in the current analysis. Estimating the risk-benefit balance in elderly patients is challenging. Surgeons or patients may be hesitant to undergo surgery with a potential for undertreatment. On the other hand, if the risks are underestimated, 
there is potential for overtreatment. Although the current results do not suggest denying curative intent surgery to elderly patients, these do caution surgeons to consider the incremental risk in the setting of shorter life expectancy for older patients and limited overall survival for GC treated with curative intent [2, 4]. Moreover, surgery can also negatively impact postoperative lifestyle and lifespan. Disseminating the current data will contribute to raising awareness to improve risk assessment and patient counseling before surgery. Tailored interventions driven by procedure-specific data as provided herein are known to be critical in ensuring successful and lasting impact [43]. The inclusion in the ACS-NSQIP registry of gastrectomy for GC performed in frail patients, including ASA IV and V, further supports the need for the current work to support refined surgical selection. Surgeons' awareness of increased surgical risk is the first step in identifying high-risk elderly patients.

It is acknowledged that this study is limited by biases inherent to retrospective designs. Despite detailed multivariable analyses, unknown confounders and variables cannot be taken completely into account. The analysis is limited by the information available in the ACS-NSQIP. The ACS-NSQIP lacks cancer-specific variables including staging and tumor location (gastroesophageal junction vs. pure gastric). Operations for advanced-stage cancer can be more challenging and impact the risk for morbidity. Operative time and extent of resection were used as surrogate markers for technical complexity. Finally, morbidity stratified by the Clavien-Dindo classification or 90-day outcomes could not be reported. Nevertheless, the ACS-NSQIP provides multi-institutional clinical data captured by rigorously trained data abstractors and subjected to frequent audits to ensure accuracy, thereby providing detailed reliable outcomes information while limiting information bias [21-24]. With such large datasets, missing data can present an issue [44]. Previous studies have concluded that here is no significant change between various strategies to handle missing data in the ACS-NSQIP, such that no particular method could be recommended [44]. In this analysis, the amount of missing data on key covariates was limited and missing data were not associated with the exposure (age). Thus, patients with missing data were excluded.

\section{Conclusions}

Advanced age beyond 75 years old was independently associated with increased morbidity after GC resection. The independent incremental risk associated with age is further modulated by the clinical scenario including functional status, comorbidities, and extent of surgery. Increased surgical risk for elderly GC patients should be acknowledged and considered when making individual decision regarding resection. Future work balancing survival gain against the morbidity cost to achieve it is warranted for further clinical guidance.

\section{Compliance with ethical standards}

Conflict of interest The American College of Surgeons National Surgical Quality Improvement Program and the hospitals participating in the ACS-NSQIP are the source of the data used herein; they have not verified and are not responsible for the statistical validity of the data analysis or the conclusions derived by the authors. The authors have no conflict of interest to disclose.

Ethical standards Approval was sought through the Sunnybrook Health Sciences Centre Research Ethics Board, and the study was deemed to be exempt.

\section{References}

1. Jemal A, Ward E, Hao Y, Thun M. Trends in the leading causes of death in the United States, 1970-2002. JAMA. 2005;294:1255-9.

2. Siegel RL, Miller KD, Jemal A. Cancer statistics, 2017. CA Cancer J Clin. 2017;67(1):7-30.

3. Hamel MB, Henderson WG, Khuri SF. Surgical outcomes for patients aged 80 and older: morbidity and mortality from major noncardiac surgery. J Am Geriatr Soc. 2005;53(5):424-9.

4. Coburn NG, Lourenco LG, Rossi SE, Gunraj N, Mahar AL, Helyer LK, et al. Management of gastric cancer in Ontario. J Surg Oncol. 2010;102:54-63.

5. Bartlett EK, Roses RE, Kelz RR, Drebin JA, Fraker DL, Karakousis GC. Morbidity and mortality after total gastrectomy for gastric malignancy using the American College of Surgeons National Surgical Quality Improvement Program database. Surgery (St. Louis). 2014;156:298-304.

6. Degiuli M, Sasako M, Ponti A. Morbidity and mortality in the Italian Gastric Cancer Study Group randomized clinical trial of D1 versus D2 resection for gastric cancer. Br J Surg. 2010;97:643-9.

7. Songun I, Putter H, Kranenbarg EMK, Sasako M, van de Velde CJ. Surgical treatment of gastric cancer: 15-year follow-up results of the randomised nationwide Dutch D1D2 trial. Lancet Oncol. 2010;11:439-49.

8. Coburn N, Seevaratnam R, Paszat L, Helyer L, Law C, Swallow C, et al. Optimal management of gastric cancer: results from an international RAND/UCLA expert panel. Ann Surg. 2014;259:102-8.

9. Takeuchi D, Koide N, Suzuki A, Ishizone S, Shimizu F, Tsuchiya $\mathrm{T}$, et al. Postoperative complications in elderly patients with gastric cancer. J Surg Res. 2015;198:317-26.

10. Mita K, Ito H, Hashimoto M, Murabayashi R, Asakawa H, Nabetani M, et al. Postoperative complications and survival after gastric cancer surgery in patients older than 80 years of age. J Gastrointest Surg. 2013;17:2067-73.

11. Hsu J-T, Liu M-S, Wang F, Chang C-J, Hwang T-L, Jan Y-Y, et al. Standard radical gastrectomy in octogenarians and nonagenarians with gastric cancer: are short-term surgical results and long-term survival substantial? J Gastrointest Surg. 2012;16:728-37.

12. Cho GS, Kim W, Kim HH, Ryu SW, Kim MC, Ryu SY. Multicentre study of the safety of laparoscopic subtotal gastrectomy for gastric cancer in the elderly. Br J Surg. 2009;96:1437-42.

13. Hwang SH, Park Do Joong, Jee YS, Kim H-H, Lee H-J, Yang $\mathrm{H}-\mathrm{K}$, et al. Risk factors for operative complications in elderly patients during laparoscopy-assisted gastrectomy. JACS. 2009;208:186-92. 
14. Orsenigo E, Tomajer V, Di Palo S, Carlucci M, Vignali A, Tamburini A, et al. Impact of age on postoperative outcomes in 1118 gastric cancer patients undergoing surgical treatment. Gastric Cancer. 2007;10:39-44.

15. Sakurai K, Muguruma K, Nagahara H, Kimura K, Toyokawa T, Amano R, et al. The outcome of surgical treatment for elderly patients with gastric carcinoma. J Surg Oncol. 2015;111:848-54.

16. Takeshita H, Ichikawa D, Komatsu S, Kubota T, Okamoto K, Shiozaki A, et al. Surgical outcomes of gastrectomy for elderly patients with gastric cancer. World J Surg. 2013;37:2891-8.

17. Yang J-Y, Lee H-J, Kim TH, Huh Y-J, Son Y-G, Park J-H, et al. Short- and long-term outcomes after gastrectomy in elderly gastric cancer patients. Ann Surg Oncol. 2016;24:1-9.

18. Tran TB, Worhunsky DJ, Squires MH, Jin LX, Spolverato G, Votanopoulos KI, et al. Outcomes of gastric cancer resection in octogenarians: a multi-institutional study of the U.S. Gastric Cancer Collaborative. Ann Surg Oncol. 2015;22:4371-9.

19. Kumagai K, Hiki N, Nunobe S, Jiang X, Kubota T, Aikou S, et al. Potentially fatal complications for elderly patients after laparoscopyassisted distal gastrectomy. Gastric Cancer. 2014;17:548-55.

20. Benchimol EI, Smeeth L, Guttmann A, Harron K, Moher D, Petersen I, et al. The reporting of studies conducted using observational routinely-collected health data (RECORD) statement. PLoS Med. 2015;12:e1001885.

21. Shiloach M, Frencher SK, Steeger JE, Rowell KS, Bartzokis K, Tomeh MG, et al. Toward robust information: data quality and interrater reliability in the American College of Surgeons National Surgical Quality Improvement Program. J Am Coll Surg. 2010;210:6-16.

22. Henderson WG, Daley J. Design and statistical methodology of the national surgical quality improvement program: why is it what it is? Am J Surg. 2009;198:S19-27.

23. Cohen ME, Ko CY, Bilimoria KY, Zhou L, Huffman K, Wang X, et al. Optimizing ACS NSQIP modeling for evaluation of surgical quality and risk: patient risk adjustment, procedure mix adjustment, shrinkage adjustment, and surgical focus. J Am Coll Surg. 2013;217(2):336e1-346e1.

24. Davenport DL, Holsapple CW, Conigliaro J. Assessing surgical quality using administrative and clinical data sets: a direct comparison of the University Health System Consortium Clinical Database and the National Surgical Quality Improvement Program data set. Am J Med Qual. 2009;24:395-402.

25. Kurian AA, Wang L, Grunkemeier G, Bhayani NH, Swanström LL. Defining "the elderly" undergoing major gastrointestinal resections. Ann Surg. 2013;258:483-9.

26. Elmi M, Mahar A, Kagedan D, Law CHL, Karanicolas PJ, Lin Y, et al. The impact of blood transfusion on perioperative outcomes following gastric cancer resection: an analysis of the American College of Surgeons National Surgical Quality Improvement Program database. Can J Surg Can Med Assoc. 2016;59:322-9.

27. Hallet J, Mahar AL, Tsang ME, Lin Y, Callum J, Coburn NG, et al. The impact of peri-operative blood transfusions on post-pancreatectomy short-term outcomes: an analysis from the American College of Surgeons National Surgical Quality Improvement Program. HPB (Oxf). 2015;17(11):975-82.

28. Parikh P, Shiloach M, Cohen ME, Bilimoria KY, Ko CY, Hall BL, et al. Pancreatectomy risk calculator: an ACS-NSQIP resource. HPB (Oxf). 2010;12:488-97.

29. Hayashi M, Inoue Y, Komeda K, Shimizu T, Asakuma M, Hirokawa $\mathrm{F}$, et al. Clinicopathological analysis of recurrence patterns and prognostic factors for survival after hepatectomy for colorectal liver metastasis. BMC Surg. 2010;10:27.

30. Bittner R, Butters M, Ulrich M, Uppenbrink S, Beger HG. Total gastrectomy. Updated operative mortality and long-term survival with particular reference to patients older than 70 years of age. Ann Surg. 1996;224:37-42.

31. Al-Refaie WB, Parsons HM, Henderson WG, Jensen EH, Tuttle TM, Vickers SM, et al. Major cancer surgery in the elderly: results from the American College of Surgeons National Surgical Quality Improvement Program. Ann Surg. 2010;251:311-8.

32. United Nations. Ageing [Internet]. United Nations. [cited 2017 May]. https://www.un.org/en/sections/issues-depth/ageing/index. html.

33. The World Health Organization. World report on ageing and health [Internet]. 2015 [cited 2017 May]. https://apps.who.int/iris/bitstr eam/10665/186463/1/9789240694811_eng.pdf?ua=1.

34. Eguchi T, Takahashi Y, Ikarashi M, Kasahara M, Fujii M. Is extended lymph node dissection necessary for gastric cancer in elderly patients? Eur J Surg. 2000;166(12):949-53.

35. Matsushita I, Hanai H, Kajimura M, Tamakoshi K, Nakajima T, Matsubayashi Y, et al. Should gastric cancer patients more than 80 years of age undergo surgery? comparison with patients not treated surgically concerning prognosis and quality of life. J Clin Gastroenterol. 2002;35:29-34.

36. Hayashi T, Yoshikawa T, Aoyama T, Ogata T, Cho H, Tsuburaya A. Severity of complications after gastrectomy in elderly patients with gastric cancer. World J Surg. 2012;36:2139-45.

37. Ghaferi AA, Osborne NH, Birkmeyer JD, Dimick JB. Hospital characteristics associated with failure to rescue from complications after pancreatectomy. J Am Coll Surg. 2010;211:325-30.

38. Macdonald JS, Smalley SR, Benedetti J, Hundahl SA, Estes NC, Stemmermann GN, et al. Chemoradiotherapy after surgery compared with surgery alone for adenocarcinoma of the stomach or gastroesophageal junction. N Engl J Med. 2001;345:725-30.

39. Cunningham D, Allum WH, Stenning SP, Thompson JN, Van de Velde CJH, Nicolson M, et al. Perioperative chemotherapy versus surgery alone for resectable gastroesophageal cancer. N Engl J Med. 2006;355:11-20.

40. McMillan MT, Allegrini V, Asbun HJ, Ball CG, Bassi C, Beane $\mathrm{JD}$, et al. Incorporation of procedure-specific risk into the ACSNSQIP surgical risk calculator improves the prediction of morbidity and mortality after pancreatoduodenectomy. Ann Surg. 2017;265:978-86.

41. Lyle B, Landercasper J, Johnson JM, Al-Hamadani M, Vang CA, Groshek J, et al. Is the American College of Surgeons National Surgical Quality Improvement Program surgical risk calculator applicable for breast cancer patients undergoing breast-conserving surgery? Am J Surg. 2016;211:820-3.

42. Etzioni DA, Liu JH, Maggard MA, Ko CY. The aging population and its impact on the surgery workforce. Ann Surg. 2003;238:170-7.

43. Cabana MD, Rand CS, Powe NR, Wu AW, Wilson MH, Abboud $\mathrm{PA}$, et al. Why don't physicians follow clinical practice guidelines? a framework for improvement. JAMA. 1999;282:1458-65.

44. Parsons HM, Henderson WG, Ziegenfuss JY, Davern M, Al-Refaie WB. Missing data and interpretation of cancer surgery outcomes at the American College of Surgeons National Surgical Quality Improvement Program. J Am Coll Surg. 2011;213:379-91. 


\section{Affiliations}

Trevor D. Hamilton ${ }^{1,2}$ - Alyson L. Mahar ${ }^{3}$. Barbara Haas ${ }^{4,5}$ - Kaitlyn Beyfuss ${ }^{5}$. Calvin H. L. Law ${ }^{4,5}$. Paul J. Karanicolas ${ }^{4,5}$. Natalie G. Coburn ${ }^{4,5}$. Julie Hallet ${ }^{4,5}$

1 Department of Surgery, University of British Columbia, Vancouver, BC, Canada

2 Department of Surgery, Vancouver General Hospital, Vancouver, BC, Canada

3 Department of Public Health Sciences, Queen's University, Kingston, ON, Canada
4 Department of Surgery, University of Toronto, Toronto, ON, Canada

5 Division of General Surgery, Sunnybrook Health Sciences, 2075 Bayview Ave., T2-063, Toronto, ON M4N 3M5,

Canada 